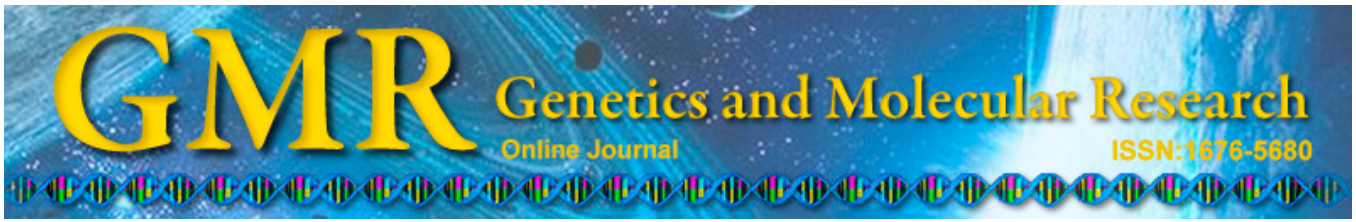

\title{
Cloning and sequence analysis of sucrose phosphate synthase gene from varieties of Pennisetum species
}

\author{
H.C. Li ${ }^{1,2}$, H.B. Lu ${ }^{1,2}$, F.Y. Yang ${ }^{1,2}$, S.J. Liu ${ }^{1,2}$, C.J. Bai ${ }^{3}$ and Y.W. Zhang ${ }^{1,2}$ \\ ${ }^{1}$ Beijing Key Laboratory for Grassland Science, China Agricultural University, \\ Beijing, China \\ ${ }^{2}$ National Energy R\&D Center for Biomass, China Agricultural University, \\ Beijing, China \\ ${ }^{3}$ Key Laboratory of Crop Gene Resources and Germplasm Enhancement in \\ Southern China, Ministry of Agriculture, \\ Tropical Crops Genetic Resources Institute, CATAS, Danzhou, \\ Hainan, China \\ Corresponding author: Y.W. Zhang \\ E-mail: zywei@126.com
}

Genet. Mol. Res. 14 (1): 2799-2808 (2015)

Received February 28, 2014

Accepted July 23, 2014

Published March 31, 2015

DOI http://dx.doi.org/10.4238/2015.March.31.10

ABSTRACT. Sucrose phosphate synthase (SPS) is an enzyme used by higher plants for sucrose synthesis. In this study, three primer sets were designed on the basis of known SPS sequences from maize (GenBank: NM_001112224.1) and sugarcane (GenBank: JN584485.1), and five novel SPS genes were identified by RT-PCR from the genomes of Pennisetum spp (the hybrid $P$. americanum $\mathrm{x}$ P. purpureum, P. purpureum Schum., P. purpureum Schum. cv. Red, P. purpureum Schum. cv. Taiwan, and $P$. purpureum Schum. cv. Mott). The cloned sequences showed $99.9 \%$ identity and $80-88 \%$ similarity to the SPS sequences of other plants. The SPS gene of hybrid Pennisetum had one nucleotide and four amino acid polymorphisms compared to the other four germplasms, and cluster analysis was performed to assess genetic diversity in this species. 
Additional characterization of the SPS gene product can potentially allow Pennisetum to be exploited as a biofuel source.

Key words: Pennisetum Rich.; Sucrose phosphate synthase; Gene clone; Sequence analysis

\section{INTRODUCTION}

Pennisetum Rich. is a fast-growing annual or perennial herb distributed in tropical and subtropical regions, which has multiple tillers and a high biomass and can be grown in barren, sandy, or saline-alkaline soil (Liu, 2009; Zhang, 2012). Elephant grass and hybrid Pennisetum are typical examples of this genus. Hybrid Pennisetum serves as raw material for energy conversion, with a per hectare yield of nearly 11 tons. It cannot only be directly burned to generate power, but can also be converted into ethanol or gas (Morais et al., 2009; Fan et al., 2012).

Converting plant starches into sugar and then ethanol is a highly efficient method of obtaining energy from biomass (Xu and Liu, 2009). Although this process is often applied to sweet sorghum, it is limited by crop yields. Thus, using perennial grasses that have widespread distribution and high sugar content is a potential solution to the shortage of available plant sources.

Sucrose is the main sugar produced by photosynthesis, and sucrose phosphate synthase (SPS) is a key enzyme in this process. SPS was initially purified as a relatively low abundance and unstable enzyme from wheat germ, and SPS gene expression was thereafter detected in mesophyll cells of maize and rice (Liu et al., 2005; Wei, 2011). Some studies have indicated that the activity of SPS can be improved by transferring foreign genes into crops, resulting in a corresponding increase in sugar production (Worrell et al., 1991); this technology has been applied to sugar beet (Liu et al., 2010), maize (Liu, 2003), and sweet sorghum (Liu et al., 2011). However, there are no reports of the cloning and expression of the SPS gene in an energy-rich plant such as Pennisetum. Elephant grass (including red and dwarf types), hybrid Pennisetum and Taiwan sweet grass are representative varieties of Pennisetum Rich. that are widely cultivated in southern China and have high yield, and their SPS activity can potentially be exploited as a source of energy.

In this study, five gene segments were cloned from the genomes of five varieties of Pennisetum Rich. using the homologous gene sequence method. Sequence identity and evolutionary conservation were analyzed, including nucleotide and amino acid polymorphisms. The results revealed both conservation and polymorphism in the SPS gene of different varieties of Pennisetum Rich.

\section{MATERIAL AND METHODS}

\section{Plant materials}

Five varieties of Pennisetum were cultivated in a greenhouse: a Pennisetum hybrid ( $P$. americanus $\mathrm{x}$ P. purpureum) was from Beijing, while elephant grass ( $P$. purpureum Schum.), red elephant grass (P. purpureum Schum. cv. Red), Taiwan sweet grass (P. purpureum Schum. cv. Taiwan), and dwarf elephant grass (P. purpureum Schum. cv. Mott) were from Hainan. 


\section{Total RNA isolation}

Fresh young leaves $(0.5 \mathrm{~g})$ were flash frozen in liquid nitrogen and ground into a powder. Total RNA was immediately isolated using an RNA extraction kit (Tiangen Biotech, Beijing, China) according to manufacturer instructions, and stored in Tris-HCl/EDTA buffer, $\mathrm{pH} 8.0$, at $-80^{\circ} \mathrm{C}$ until use. The quality of the RNA samples was evaluated by $1.2 \%$ agarose gel electrophoresis and the $260 / 280$-nm absorbance ratio, which was determined using a NanoDrop 2000 spectrophotometer (Thermo Scientific, USA).

\section{First-strand cDNA synthesis and PCR amplification}

RNA was reverse-transcribed to cDNA using the First-Strand cDNA Synthesis kit (Tiangen Biotech) according to the manufacturer protocol; the cDNA was stored at $-20^{\circ} \mathrm{C}$ until use.

Three sets of primers were designed on the basis of the SPS coding sequence for maize using the Primer 5.0 software, and synthesized by Sangon Biotech (Shanghai, China). Forward primer (PF) and reverse primer (PR) sequences are shown in Table 1.

Table 1. Primer sequences for cloning sucrose phosphate synthase from Pennisetum Rich.

\begin{tabular}{lll}
\hline Primer set & Name & Sequence $\left(5^{\prime} \rightarrow 3^{\prime}\right)$ \\
\hline 1 & PF1 & AACCCTCACAAGCC \\
2 & PR1 & CGCACGGAAAGATA \\
& PF2 & AGCAGGTTGGAAATGG \\
3 & PR2 & GACAGACGGAGTGACAGG \\
& PF3 & GGCGTTCCCTAAGCATCACA \\
\hline
\end{tabular}

$\mathrm{PF}=$ forward primer; $\mathrm{PR}=$ reverse primer.

The amplification reaction mixture $(50 \mu \mathrm{L})$ contained the following: $100 \mathrm{ng}$ cDNA, $25 \mu \mathrm{L} 2 \mathrm{X}$ Taq Platinum PCR MasterMix (Tiangen Biotech), $2 \mu \mathrm{L}$ of each primer $(10 \mu \mathrm{M})$,

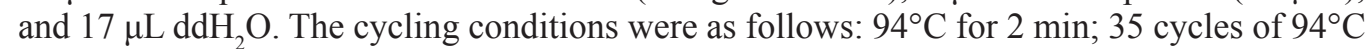
for $30 \mathrm{~s}, 40^{\circ}-45^{\circ} \mathrm{C}$ (depending on the primer) for $30 \mathrm{~s}, 72^{\circ} \mathrm{C}$ for $1 \mathrm{~min}$; and $72^{\circ} \mathrm{C}$ for $10 \mathrm{~min}$.

PCR products were resolved by $1.2 \%$ agarose gel electrophoresis and purified using a gel extraction kit (Tiangen Biotech). Purified products were ligated into the PMD18-T vector (Takara, Dalian, China), which was used to transform Escherichia coli DH5 $\alpha$ competent cells. Positive clones were selected on Luria broth/agar plates containing ampicillin (100 $\mu \mathrm{g} / \mathrm{mL})$, IPTG $(100 \mu \mathrm{g} / \mathrm{mL})$, and X-gal $(40 \mu \mathrm{g} / \mathrm{mL})$. After confirming the successful insertion of the amplification product by colony PCR using primer set 1 (PF1, PR1), clones were sequenced.

\section{Data analysis}

Sequences obtained for the Pennisetum SPS gene were compared to known sequences in the NCBI database using BLASTX. Multiple-sequence alignments and analysis of genetic diversity were performed by using Vector NTI, DNAman, and DNAStar software programs, while ClustalW was used for cluster analysis. 


\section{RESULTS}

\section{Analysis of the SPS gene sequence}

PCR products amplified from the genome of five varieties of Pennisetum are shown in Figure 1. The band between 1 and $2 \mathrm{~kb}$ corresponded to the predicted size of the SPS coding sequence.

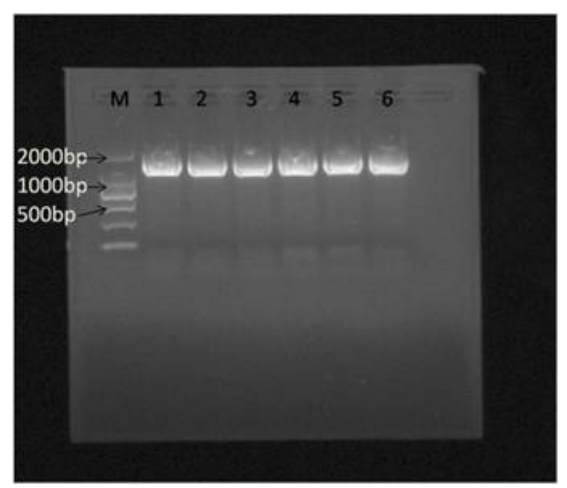

Figure 1. PCR products amplified from Pennisetum cDNA (lanes 1-6) using primers PF1 and PR1 and an annealing temperature of $40.3^{\circ} \mathrm{C}$. Details of the procedure are described in Material and Methods. Lane $M=$ DNA marker; lane 1 = elephant grass; lane 2 = Taiwan sweet grass; lane 3 = red elephant grass; lane $4=$ dwarf elephant grass; lanes 5 and $6=$ hybrid Pennisetum.

Sequence fragments were spliced using the DNAman software, and the total length was found to be $1408 \mathrm{bp}$. The SPS gene of dwarf elephant grass and Pennisetum hybrid encodes 445- and 444-amino acid proteins, respectively, which was also the case for the other three clones. The sequences showed 99.9\% identity; using the NCBI BLASTn search, the sequences were found to share identity with Setaria italica (foxtail millet; 96\%), hybrid sugarcane $(88 \%)$, maize $(87 \%)$, sugarcane $(86 \%)$, sorghum (88\%), Brachypodium distachyon (purple false brome; $81 \%$ ), and wheat (80\%), indicating that the SPS gene in Pennisetum was highly homologous to that of other plants (Figure 2).

\begin{tabular}{|c|c|c|c|c|c|c|c|}
\hline & Description & $\begin{array}{l}\text { Max } \\
\text { score }\end{array}$ & $\begin{array}{l}\text { Total } \\
\text { score }\end{array}$ & $\begin{array}{l}\text { Query } \\
\text { cover }\end{array}$ & $\underset{\text { value }}{E}$ & Ident & Accession \\
\hline$\Gamma$ & PREDICTED: Setaria italica sucrose-phosphate synthase-like (LOC10176043 & 2263 & 2263 & $100 \%$ & 0.0 & $96 \%$ & $\underline{X M} \quad 004971009.1$ \\
\hline 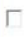 & Saccharum hybrid cultivar ROC22 sucrose phosphate synthase B (SPSB) $\mathrm{mF}$ & 1644 & 1644 & $100 \%$ & 0.0 & $88 \%$ & JN584485.1 \\
\hline$\Gamma$ & Sorghum bicolor hypothetical protein, MRNA & 1628 & 1628 & $100 \%$ & 0.0 & $88 \%$ & XM_002458946.1 \\
\hline$\Gamma$ & Zea mays sucrose phosphate synthase1 (sps1), mRNA >gb|M97550.1/MZES & 1550 & 1550 & $100 \%$ & 0.0 & $87 \%$ & NM_001112224.1 \\
\hline$\Gamma$ & Saccharum officinarum mRNA for Sucrose-Phosphate Synthase, partial cds & 1511 & 1511 & $100 \%$ & 0.0 & $86 \%$ & $\underline{A B 001337.1}$ \\
\hline$\Gamma$ & Zea mays full-length cDNA cione ZM_BFb0215J14 mRNA, complete cds & 1182 & 1182 & $80 \%$ & 0.0 & $86 \%$ & BT055092.1 \\
\hline$\Gamma$ & PREDICTED: Brachypodium distachyon sucrose-phosphate synthase-like (LC & 1061 & 1061 & $99 \%$ & 0.0 & $81 \%$ & XM_003564887.1 \\
\hline$\Gamma$ & Zea mays CL2428_1 mRNA sequence & 1016 & 1424 & $95 \%$ & 0.0 & $84 \%$ & AY109574.1 \\
\hline$\Gamma$ & Triticum aestivum sucrose-phosphate synthase $5 \mathrm{mRNA}$, partial cds & 996 & 996 & $99 \%$ & 0.0 & $80 \%$ & Af347067.1 \\
\hline & Triticum aestivum cDNA, clone: WTO13_F14, cultivar: Chinese Spring & 990 & 990 & $99 \%$ & 0.0 & $80 \%$ & AK335612.1 \\
\hline$\Gamma$ & Hordeum vulgare subsp. vulgare cDNA clone: FLbaf138m10, mRNA sequenc & 760 & 760 & $78 \%$ & 0.0 & $79 \%$ & AK251897.1 \\
\hline
\end{tabular}

Figure 2. Homology of the Pennisetum SPS gene sequence to that of other plant species. 
The amino acid sequence identity for the five clones was $99.55 \%$, indicating a highly conserved protein. There was low absolute complexity between individual amino acids that had low identity (Figure 3). The absolute complexity of residues 314-318 in hybrid Pennisetum was significantly different from that of four other plant species (Figure 4), suggesting that these residues may confer a property or function unique to Pennisetum SPS. Overall, the amino acid sequence shared identity with $S$. italica $(96 \%)$, maize $(90 \%)$, sugarcane hybrid $(89 \%)$, sorghum (89\%), sugarcane (87\%), B. distachyon (81\%), and wheat (80\%) (Figure 5).

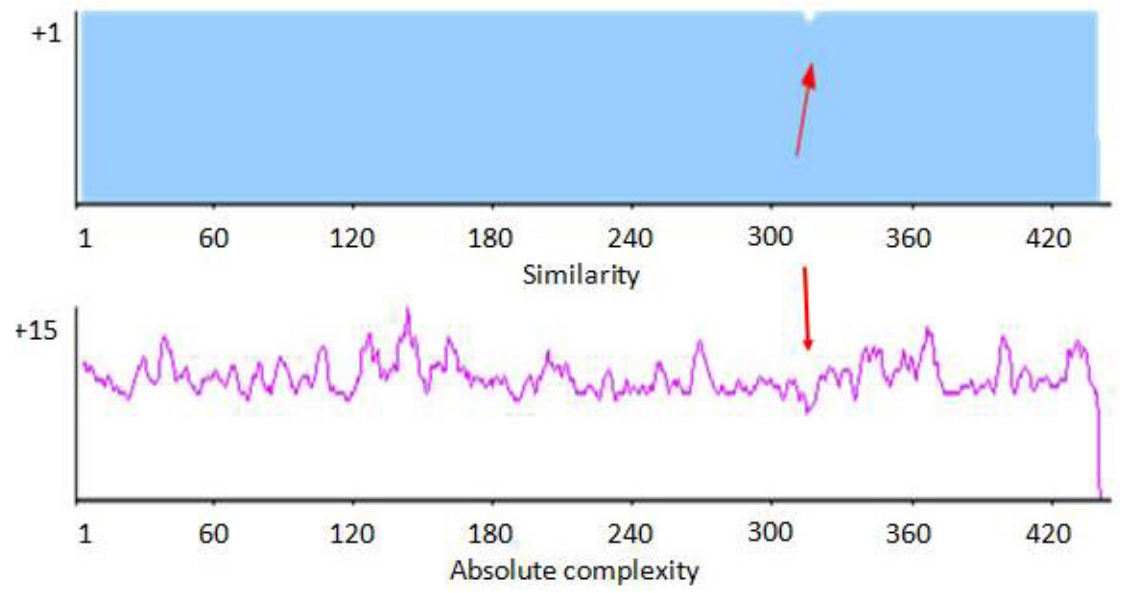

Figure 3. Similarity and absolute complexity of the SPS amino acid sequence.

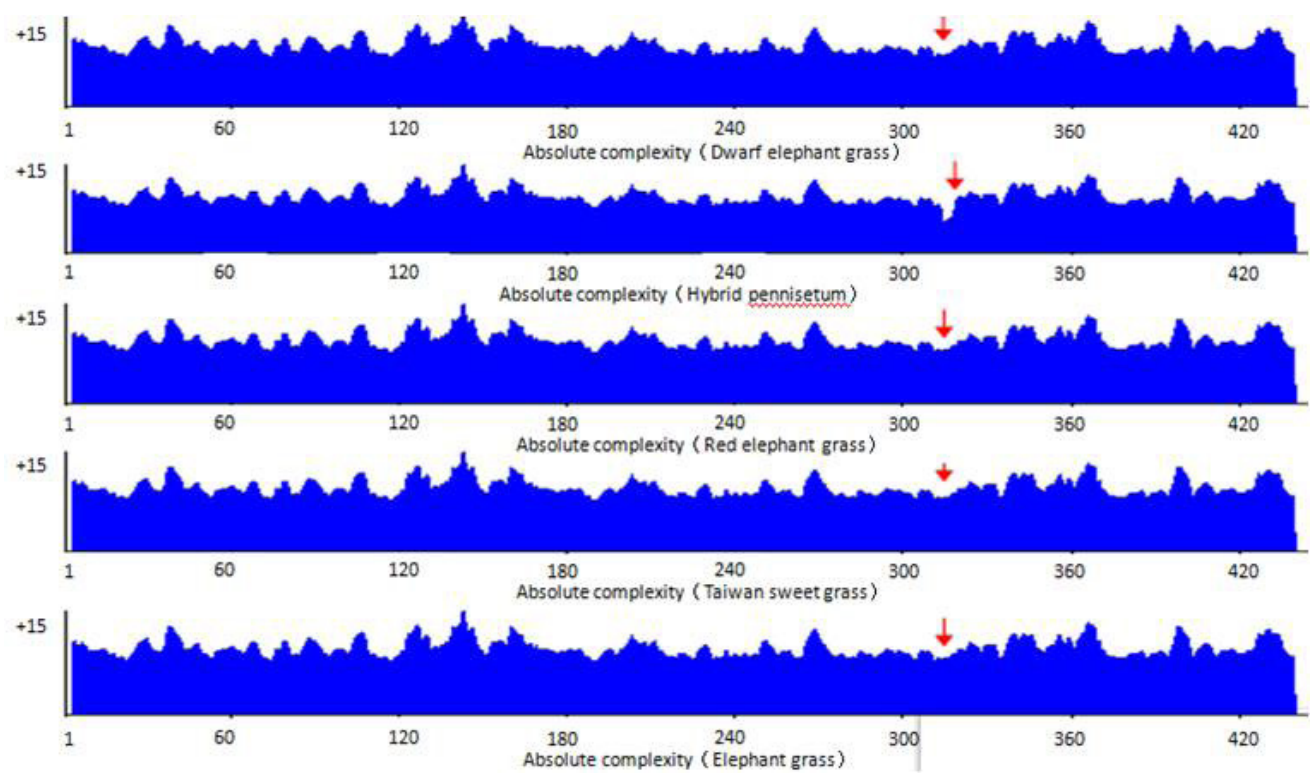

Figure 4. Similarity and absolute complexity of the Pennisetum SPS amino acid sequence to that of five plant species. 


Description
$\Gamma$ PREDICTED: sucrose-phosphate synthase-like [Setaria italica]
$\Gamma$ hypothetical protein SORBIDRAFT 03g043900 [Sorghum bicolor] >gb|EESO4
$\Gamma$ TPA: putative sucrose-phosphate synthase familly protein [Zea mays]
$\Gamma$ sucrose-phosphate synthase [Zea mays] >sp]P31927.1/SPS MAIZE RecNan
$\Gamma$ sucrose phosphate synthase B [Saccharum hybrid cultivar ROC22]
$\Gamma$ Sucrose-Phosphate Synthase [Saccharum officinarum]
$\Gamma$ PREDICTED: sucrose-phosphate synthase-like [Brachypodium distachyon]
$\Gamma$ sucrose-phosphate synthase 5. partial [Triticum aestivum]
$\Gamma$ Sucrose-phosphate synthase [Aegilops tauschil]
$\Gamma$ RecName: Full=Probable sucrose-phosphate synthase 1; AltName: Full=UDP

\begin{tabular}{|c|c|c|c|c|c|}
\hline $\begin{array}{l}\text { Max } \\
\text { score }\end{array}$ & $\begin{array}{l}\text { Total } \\
\text { score }\end{array}$ & $\begin{array}{l}\text { Query } \\
\text { cover }\end{array}$ & $\begin{array}{c}E \\
\text { value }\end{array}$ & Ident & Accession \\
\hline 873 & 873 & $100 \%$ & 0.0 & $96 \%$ & XP_004971066.1 \\
\hline 816 & 816 & $100 \%$ & 0.0 & $89 \%$ & XP 002458991.1 \\
\hline 817 & 817 & $100 \%$ & 0.0 & $90 \%$ & DAA56138.1 \\
\hline 813 & 813 & $100 \%$ & 0.0 & $89 \%$ & NP 001105694.1 \\
\hline 813 & 813 & $100 \%$ & 0.0 & $89 \%$ & AEO 46461.1 \\
\hline 786 & 786 & $100 \%$ & 0.0 & $87 \%$ & BAA19241.1 \\
\hline 742 & 742 & $100 \%$ & 0.0 & $81 \%$ & XP 003564935.1 \\
\hline 723 & 723 & $100 \%$ & 0.0 & $80 \%$ & AAQ15109.1 \\
\hline 724 & 724 & $100 \%$ & 0.0 & $80 \%$ & EMT16825.1 \\
\hline 701 & 701 & $100 \%$ & 0.0 & $81 \%$ & A2WYE9.2 \\
\hline
\end{tabular}

Figure 5. Homology of the Pennisetum SPS amino acid sequence to that of other plant species.

\section{Nucleotide and amino acid polymorphisms among Pennisetum varieties}

A variation in the nucleotide sequence of the five SPS clones was observed upon comparison using DNAman and DNAstar software programs (Figure 6). A T $\rightarrow$ C transition at 1017 bp (Figure 6A) resulted in the substitution of Leu by Pro (Figure 7) in hybrid Pennisetum. Analysis of the amino acid sequences revealed polymorphisms at four sites. At residue 315, hybrid Pennisetum had a Leu residue, while other varieties had Pro; and at residues 441-443, Val-Pro-Leu was found in hybrid Pennisetum and dwarf elephant grass, while Ser-Leu-Cys was present in the other three varieties (Figure 7).

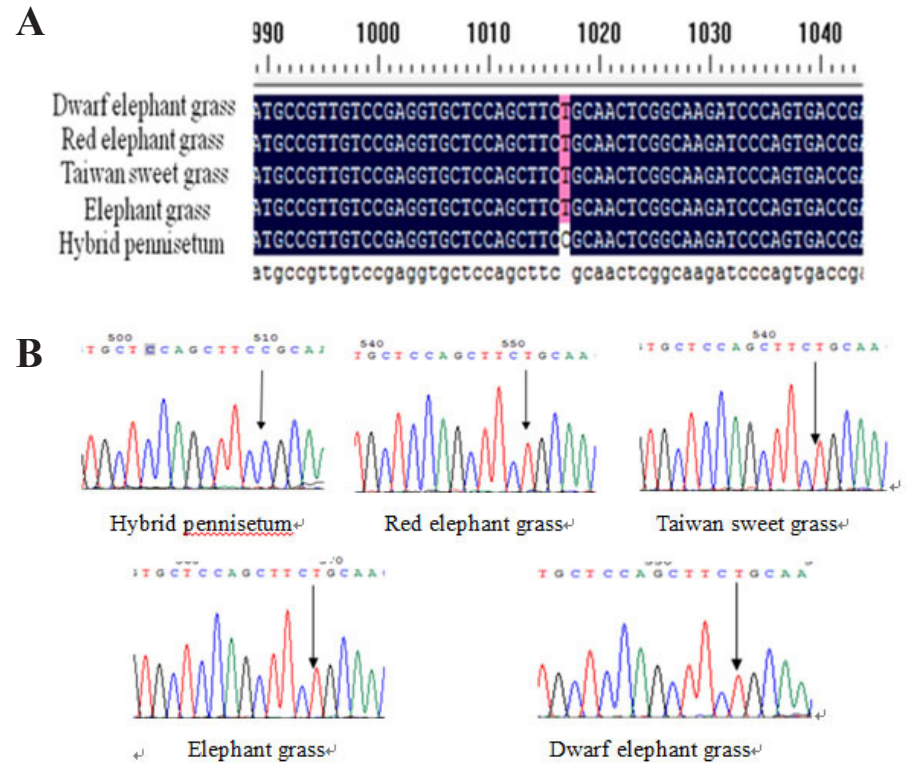

Figure 6. Single nucleotide polymorphism in the SPS gene of five Pennisetum varieties, as seen in (A) sequence alignment and (B) chromatograms. 


\begin{tabular}{|c|c|c|}
\hline & & 420 \\
\hline & 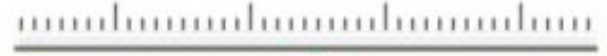 & แl, \\
\hline Dwarf elephant grass & 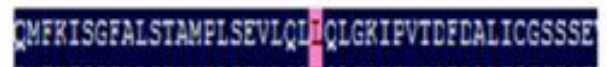 & ERLRYRGLRCHIYYCRUSTRLCWVE: \\
\hline Red elephant grass & OH-XIGRIFVIDEDAL & ERLRURGLACATYYCRNSTRLON SLC \\
\hline Taiwan sweet grass & 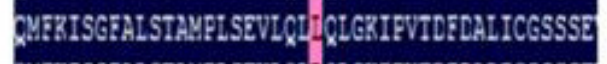 & 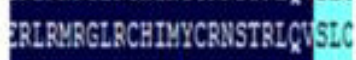 \\
\hline Elephant grass & 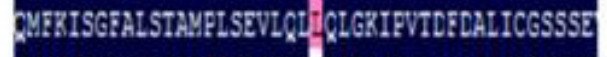 & ERLRURGLRCATYYCRMSTRLWWSLC \\
\hline Hybrid pennisetum & 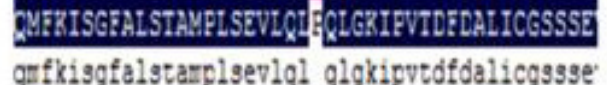 & BLPURGLRCHTYYCRMSTRLOWVI: \\
\hline
\end{tabular}

Figure 7. Amino acid polymorphisms in the SPS sequence of five Pennisetum varieties.

\section{Genetic diversity of SPS gene fragments}

A cluster analysis of the five SPS clones was performed using ClustalW. The first cluster included hybrid Pennisetum, and another included elephant grass, dwarf and red elephant grasses, and Taiwan sweet grass, which were more closely related (Figure 8A).

Cluster analysis was performed for the SPS amino acid sequences using Vector NTI and Megalign. Hybrid Pennisetum and dwarf elephant grass clustered in one group, while the other varieties formed a second group, demonstrating a close relationship between the sequences (Figure 8B).

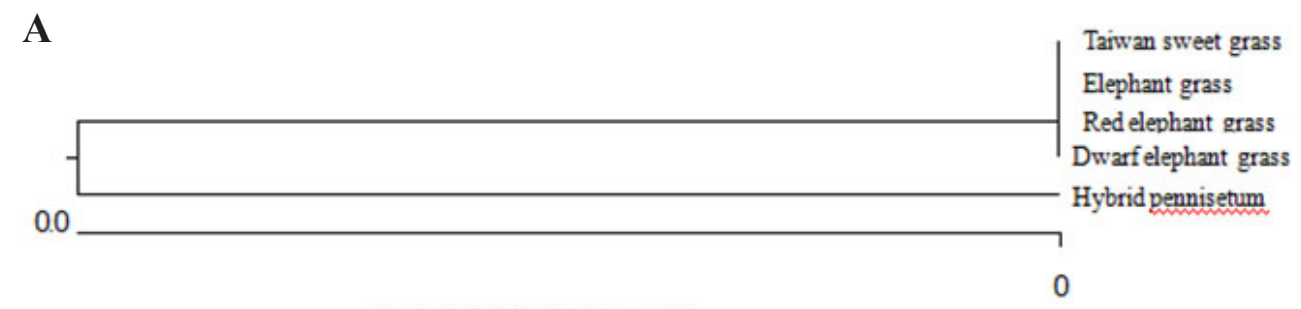

Neleotice Substitutions ( $\times 100)$

$\mathbf{B}$

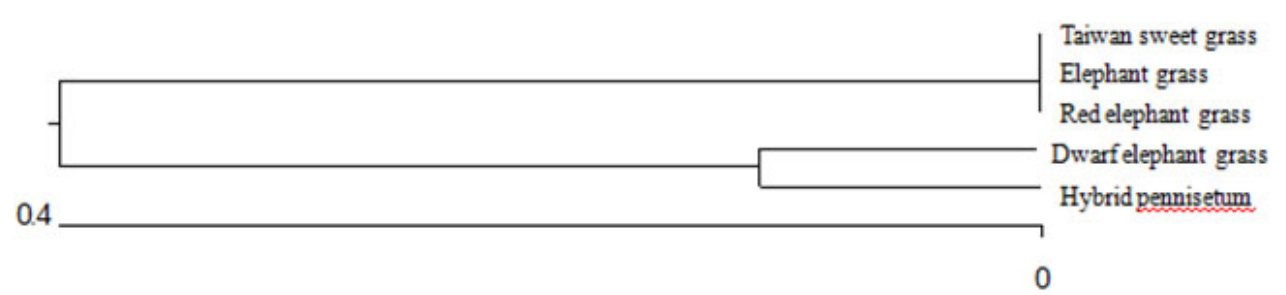

Amino Acid Sbstitutions $(x 100)$

Figure 8. Results of cluster analyses for the SPS gene in five varieties of Pennisetum. A. Nucleotide sequences were compared using Clustal W. B. Amino acid sequences were compared using Megalign, revealing two distinct clusters. 


\section{DISCUSSION}

\section{Homology of the Pennisetum SPS gene}

SPS is a key enzyme for sucrose synthesis in higher plants. As such, sucrose accumulation is positively correlated with SPS activity (Zhao et al., 2001; Park et al., 2009), and plants with relatively high sugar content such as sugar beet and sugarcane have been shown to have high SPS activity (Li et al., 2010; Ye et al., 2011). The SPS gene family has subfamilies A-C (Langenkämper et al., 2002; Zhou et al., 2006; Huang et al., 2012). In sugarcane, 10 different alleles have been identified (McIntyre et al., 2006); the gene in Dendrocalamus sinicus has $90-99 \%$ homology with other plants (He et al., 2007; Zhang et al., 2008), indicating a high degree of evolutionary conservation in this gene family. However, considerable diversity at the amino acid level was observed between Arabidopsis (Martin et al., 1993) and citrus plants because of alternative splicing (Wu and Liu, 2010b). One study used the target region amplification polymorphism approach to mark the SPS gene of sugarcane; the amplified gene exhibited high variability and rich polymorphism, indicating an inherent diversity (Xu et al., 2011). The five clones identified in the present analysis all belonged to SPS subfamily B and shared $99.9 \%$ homology (Figure 2), indicating a high degree of conservation between different varieties of the same species, but divergence from other non-congeneric types of plant. The Pennisetum SPS gene had the highest homology with foxtail millet and hybrid sugarcane (96 and $88 \%$, respectively), but relatively low homology with wheat $(80 \%)$. Similarly, nucleotide homology of the glycerol-3-phosphate acyltransferase (GPAT) gene from eight varieties of citrus plant was $97.8 \%$, while homology to other species ranged from 72.5 to $98.4 \%$ (Wu and Liu, 2010a).

\section{Variation and conservation in amino acid sequences}

A high degree of conservation at the amino acid level was also observed between the five SPS clones (99.55\%). A T to C transition at $1017 \mathrm{bp}$ resulted in the substitution of Leu by Pro in hybrid Pennisetum (Figure 7), while a 3-amino acid polymorphism was also detected: Val-Pro-Leu was found in hybrid Pennisetum and dwarf elephant grass, but Ser-Cys-Leu was present in the other three varieties, apparently due to the deletion of a $\mathrm{G}$ residue that caused a shift in the reading frame.

Cluster analysis showed divergence between hybrid Pennisetum and dwarf elephant grass, possibly due to the single-amino acid polymorphism (Leu vs Pro, respectively) at residue 315 . The analyses performed using nucleotide and amino acid sequences (Figure 8) showed different clustering patterns. The reason for this is not known; however, it is likely because certain nucleotide substitutions are conservative, and have no effect on the translated sequence.

Certain residues such as Cys, when forming disulfide bonds in the active site of enzymes, tend to be highly conserved (Guo et al., 2007). Studies of the superoxide dismutase and GPAT genes in citrus plants (Wu and Liu, 2010a) as well as in Pyrus (pear tree) (Cong et al., 2011) have shown that single nucleotide substitutions can lead to significant variation in the structure and function of the protein, causing divergence between related proteins in the final cluster analysis (Cong et al., 2011). Additional studies in hybrid Pennisetum, including mutation analyses, can shed light on the functional significance of the Leu substitution at residue 315 . 
In this study, the SPS gene in five varieties of Pennisetum Rich. was cloned and analyzed with respect to intra- and interspecies homology and evolutionary conservation. The SPS gene product plays an important role in the sucrose synthesis pathway in plants, and its activity is directly related to sucrose content (Liu et al., 2012). Given that the conversion of sucrose into a biofuel such as ethanol represents an important potential source of energy, future studies should focus on characterizing the functional and biochemical properties of Pennisetum SPS, so that Pennisetum can be exploited as a renewable energy source.

\section{ACKNOWLEGMENTS}

Research supported by the National Natural Science Foundation of China (Project \#31272493), the Ministry of Science and Technology, China (Projects \#2012AA101801, \#2011AA100209, \#2012CB215300, and \#2014FG062), and the Industry \& Technology System (forage).

\section{REFERENCES}

Cong Y, Yang SY, Song ZZ, Hao DL, et al. (2011). Cloning and expression analysis of an ammonium transporter gene in Pyrus betulaefolia and its SNP analysis in Pyrus. Acta Bot. Boreal.-Occident. Sin. 31: 1942-1950.

Fan XF, Hou XC, Zhu Y and Wu JY (2012). Biomass yield and quality of hybrid Pennisetum. Chin. J. Grassland 34: 48-52.

Guo J, Wang ST and Xu HL (2007). A new method of identifying protein conserved amino residues. J. Food Sci. Biotechnol. 26: 38-43.

He WJ, Huang JC, Zhou P, Ye BY, et al. (2007). Cloning and sequence analysis of sucrose phosphate synthase cDNA from sugarcane leaf. Subtropical Agric. Res. 3: 294-296.

Huang DL, Li SX, Liao Q, Qin CX, et al. (2012). Advances on sucrose phosphate synthase in plants. China Biotechnol. 32: 109-119.

Langenkämper G, Fung RW, Newcomb RD, Atkinson RG, et al. (2002). Sucrose phosphate synthase genes in plants belong to three different families. J. Mol. 54: 322-332.

Li JP, Wei XW and Chen XJ (2010). Cloning and expression of sucrose-phosphate synthase (BvSPS1) from beetroot and its enzyme activity analysis. Mol. Plant Breed. 8: 521-528.

Liu BH (2003). Cloning of Maize Sucrose Phosphate Synthesis Gene and Transformation into Sugar Beet. Northeast Agricultural University, Haerbin.

Liu DL, Ma LB and Hao H (2010). Cloning and sequence analysis of sucrose phosphate synthase from sugarbeet (BvSPS). Sugar Crops China 4: 6-8.

Liu LD (2009). Utilization of the high quality hybrid Pennisetum. Inner Mongolia Agric. Sci. Technol. 5: 86-87.

Liu LX, Shen FF, Lu HQ, Han QD, et al. (2005). Research advance on sucrose phosphate synthase in sucrose metabolism. Mol. Plant Breed. 3: 275-281.

Liu Y, Dun BQ and Zhang BM (2011). Isolation and characterization of sucrose phosphate synthase gene (SPS3-1) in sweet sorghum (Sorghum bicolor (L.) Moench.). Mol. Plant Breed. 9: 357-363.

Liu Y, Lin XH, Yao YL, et al. (2012). Sucrose metabolism in higher plants. Chin. Agric. Sci. Bull. 28: 145-152.

Martin T, Frommer WB, Salanoubal M and Willmitzer L (1993). Expression of an Arabidopsis sucrose synthase gene indicates a role in metabolization of sucrose both during phloem loading and in sink organs. Plant J. 4: 367-377.

McIntyre CL, Jackson M, Cordeiro GM, Amouyal O, et al. (2006). The identification and characterisation of alleles of sucrose phosphate synthase gene family III in sugarcane. Mol. Breed. 18: 39-50.

Morais RF, Souza BJ, Leite JM and Soares LHB (2009). Elephant grass genotypes for bioenergy production by direct biomass combustion. Pesq. Agropec. Bras. 44: 133-140.

Park JY, Canam T and Kang KY (2009). Sucrose phosphate synthase expression influences poplar phenology. Tree Physiol. 29: 937-946.

Wei X (2011). Expression of Sucrose Phosphate Synthase Gene and its Influence to Sugar Accumulation in Sweet Sorghum. Shenyang Normal University, Shenyang.

Worrell AC, Bruneau JM, Summerfelt K and Boersig M, et al. (1991). Expression of a maize sucrose phosphate synthase in tomato alters leaf carbohydrate partitioning. Plant Cell 3: 1121-1130. 
Wu B and Liu Y (2010a). Cloning of partial sequence of GPAT gene in citrus and its SNP analysis. Acta Agric. Univ. Jiangxiensis 32: 51-56.

Wu B and Liu Y (2010b). Cloning of SOD gene segments and SNP analysis in citrus. J. Anhui Agric. Sci. 38: 1171911724.

Xu LP, Que YX and Su YC (2011). Genetic diversity among sugarcane genotypes based on polymorphisms in sucrose metabolism genes. Sci. Agric. Sin. 44: 1788-1797.

Xu Y and Liu HY (2009). Development and expectation of the energy plant. Chin. Agric. Sci. Bull. 25: 297-300.

Ye BY, Qiu S, Zhou P, Song XM, et al. (2011). Cloning and expression analysis of sucrose-phosphate synthase II gene from sugarcane. Chin. J. Appl. Environ. Biol. 17: 673-677.

Zhang BY (2012). The Effects of Silage on Biogas Production Performance of Pennisetum american x P. purpureum. China Agricultural University, Beijing.

Zhang SZ, Wang Y and Liu XZ (2008). Isolation and cloning of sucrose phosphate synthase gene (sps) from Dendrocalamus sinicus. J. Southwest Forestr. Coll. 28: 48-56.

Zhao ZZ, Zhang SL, Xu CJ, et al. (2001). Roles of sucrose-2 metabolizing enzymes in accumulation of sugars in Satsuma Mandarin Fruit. Acta Hortic. Sin. 28: 112-118.

Zhou P, Ye BY, Chen YQ, Chen RK, et al. (2006). The resent advances on sucrose phosphate synthase. Lett. Biotechnol. 17: 1001-1003. 